gender, cognitive failures and gardening. Superior SA was evident in Sardinian elders. The data underscore a need to control social desirability bias when exploring the basis of SA.

\section{PURPOSE IN LIFE AMONG CENTENARIAN OFFSPRING}

S. Marone ${ }^{2}$, L. Nussbaum ${ }^{3}$, P. Sebastiani ${ }^{3}$, T.T. Perls ${ }^{1,2}$, S.L. Andersen ${ }^{1,2}, 1$. New England Centenarian Study, Boston, Massachusetts, 2. Boston University School of Medicine, Boston, Massachusetts, 3. Boston University School of Public Health, Boston, Massachusetts

Purpose in life (PIL), a feeling of meaning and direction in life, is associated with favorable health outcomes including lower mortality and reduced risk of disease, disability, and cognitive impairment. Since centenarian offspring have been shown to have longer health spans we sought to examine whether they have higher PIL than the general population. We compared scores from the Ryff Scales of Psychological WellBeing in New England Centenarian Study offspring ( $N=296$, mean age $=81.6$ years) with a Health and Retirement Study referent group ( $\mathrm{N}=4916$, mean age $=70.4$ years). Regression analyses adjusted for age, sex, education, and marital status indicated higher PIL scores $(\mathrm{p}<.001)$ among centenarian offspring than referents, although, this difference decreased with age. This indicates that PIL is associated with the ability to delay age-associated illnesses and functional decline. PIL and its association and interaction with other psychosocial variables and health behaviors should be further investigated in this cohort.

\section{SESSION 4840 (SYMPOSIUM)}

\section{SOCIAL SUPPORT OF CHINESE OLD ADULTS- FINDINGS FROM THE CHINESE LONGITUDINAL} AGEING SOCIAL SURVEY

Chair: W. Zhang, Renmin University of China, Beijing, China

Co-Chair: P. Du, Institute of Gerontology, Renmin

University of China, China

The rapid modernization in China has changed the lives of its senior citizens more than ever before. In order to capture the current quality of life of the Chinese elderly, a baseline of Longitudinal Ageing Social Survey (CLASS) was conducted in 2014, covered 28 out of 31 Provincial areas of China $(n=$ 11,511). The survey collected information on health, mental health, intergenerational relations, and social care resources of the elderly aged $60+$. CLASS provides detailed information on social support of older adults in China, which enables further analysis on its role in enhancing of the well-being of older persons. In this panel, five researchers from China and United States will introduce their findings using the baseline data from CLASS to address a different social and health issue namely: social isolation, social and intergenerational support, hospital service utilization of Chinese elderly.

The first paper explored intergenerational support from grandparents to grandchildren and its effect on the quality of life. The second paper also found supports from grandchildren to grandparents and proved the supports could be the substitution of ageing support from adult children. The third study reported the hospital utilization patterns and found that social support as one of the significant predictors for hospital utilization. The fourth paper revealed types of social support and its determinants. The fifth study focused on the social network of the older adults in urban China, the prevalence of social isolation has been explored and compared between floating and non-floating older adults.

\section{GRANDPARENTS RAISING GRANDCHILDREN IN CHINA AND ITS EFFECTS ON THE QUALITY OF LIFE OF OLDER PEOPLE}

J. Sun, Institute of Gerontology, Renmin University of

China, Beijing, Beijing, China

Based on the data of "China Longitudinal Aging Social Survey" in 2014, this study explores situation and characteristics of the Chinese elderly who taking care of their grandchildren as well as its effects on the quality of life of older people in the Chinese cultural context.

The results show that 34 percent of the Chinese elderly caring their grandchildren. The older groups with younger age, with spouse, higher educational attainments, better physical health and living in urban areas are more likely to care their grandchildren. The empirical results show that taking care of grandchildren do not improve the older grandparents' economic benefits. However, the finding also supports that the care may enhance older grandparents'positive psychological feelings and life satisfaction. This study indicates that the older people who provide care for grandchildren especially those live in the rural left-behind families and skipped-generation families should be supported and compensated.

\section{GRANDCHILDREN AS SUPPORT AND CARE PROVIDERS TO OLDER ADULTS IN CHINA}

M. Silverstein ${ }^{1}$, L. Xu ${ }^{2}$, 1. Sociology, Syracuse University, Syracues, New York, 2. University of Texas at Arlington, Arlington, Texas

Increased life expectancy among older adults in China implies that grandparents increasingly survive long enough for their grandchildren to reach adulthood and take on elevated importance, even as smaller family size reduces the number of children and grandchildren available. This paper examined the family conditions under which grandchildren provide support and care to their grandparents. The data for our analysis derive from the 2014 wave of the Chinese Longitudinal Aging Social Survey, limited to $13.4 \%$ of respondents $(n=1,551)$ who reported requiring personal assistance to perform daily activities. Logistic regression revealed that grandparents were more likely to receive care from grandchildren when they had no son available or had daughters who did not provide care. These findings support the compensatory or substitution role of grandchildren as sources of care for their grandparents. We conclude that grandchildren may take on elevated importance as smaller single-gender families become more common in China.

\section{HOSPITAL UTILIZATION AMONG CHINESE OLDER ADULTS - PATTERNS AND PREDICTORS}

I. $\mathrm{Chi}^{1}$, H. Chen ${ }^{2}$, R. Liu ${ }^{1}$, 1. School of Social Work, LA, California, 2. Department of Social Work, Fudan University, Shanghai, China 
China's population is aging rapidly and its healthcare cost has increased tremendously in recent years. It is critical to understand the hospital utilization pattern and the predictors of utilization among older Chinese adults. This study used a national sample aged 60 and older $(n=11,511)$ who were the respondents from the China Longitudinal Aging Social Survey in 2014. About 25\% of the respondents were hospitalized in the previous year. We applied the Anderson Model of Health Services Utilization, stepwise logistic regression models to identify the predictors of hospital utilization. The results showed level of literacy, social support, negative perception of aging, and rural residency significantly predicted hospital utilization. Separate models were run for rural and urban samples with significant differences in the utility of predicting hospitalization for age, social network, ADL and IADL disability. In addition, there are variations cross provinces in the hospitalization. Policy and practice implications are discussed accordingly.

\section{PATTERNS OF SOCIAL SUPPORTS OF CHINESE ELDERLY AND ITS DETERMINANTS}

\section{J. Lu, L. Zhang, Department of Sociology, Peking}

University, Beijing, China

Early literature turn out that the patterns of social supports of the elderly in western nations are quite different from those of Chinese elderly, which indicates that more social supports for Chinese elderly depend mainly on their children and relatives. However, accompanied with process of the modernization and industrialization, the traditional patterns of social supports of Chinese elderly have changed. This study employed the CLASS data to identify the current patterns of social support and its determinants by using Logistic model. Our results show that factors such as schoolings, occupation before retirement, residence, social pension, etc., could affect the choice of social support of Chinese elderly, which urges both central and local governments to provide more social service and care for Chinese elderly in the rapid process of population ageing in China.

\section{SOCIAL ISOLATION OF OLD PEOPLE IN URBAN CHINA}

W. Zhang, R. Liu, The Institute of Gerontology, Renmin University of China, Beijing, China

With the development of urbanization in china since 1980 's, a great number of floating people become elderly, and many of migrants brought their parents into urban communities, all above changes increasing the migration of the elderly. The migration changes the social environments of the elderly, increases the probability of social isolation. Employing the data of China Longitudinal Aging Social Survey (CLASS), this study descried the situation of social isolation of the elderly in urban China, and identified differences between floating people and local citizens. A Logistic regression analysis has been conducted to reveal the determinants of social isolation, and a comparison between the non-floating elderly and floating elderly has been done. The results indicated that the living arrangement is the most important predictive factor for the family isolation, while the participation in social activities is major determinant variable for the friend isolation of the older floating people.

\section{SESSION 4845 (SYMPOSIUM)}

\section{MASCULINITY IN THE REALM OF CARE}

Chair: S. Solimeo, Department of Veterans Affairs, Center

for Comprehensive Accesss \& Delivery Research and

Evaluaiton (CADRE) Iowa City VA HCS, Iowa City, Iowa

Co-Chair: E.H. Thompson, College of the Holy Cross,

Broadview Heights, Ohio

Discussant: L.W. Kaye, University of Maine

The canon that men should be self-reliant coupled with a feminization of self-care and the labor of caring for others diminishes many men's perceived capability to engage in preventive care as well as devalues the care work they do. The research discussed in this symposium explores the gendered nature of older men's care, for self or for others, and the consequences of such gendering for the men. The first three presentations engage the performance and meaning of self-care among men. Clark and Bennett discuss how older Canadian men actively draw upon masculinity scripts of physical competency and strength to resist negative perceptions of aging bodies. Leibing's study of older Canadian men who had embraced experimental stem cell treatment for their heart disease identifies how the men's cardiac recovery also embraced common masculinity scripts. Smith's interviews with US veterans incarcerated in maximum-security prison underscore the men's unmet health needs, and resistance to self-care in a macho culture thick with violence-enforced gender performances. The final presentation addresses the performance and meaning of men's care work for others. Seaman's work studies illustrate how men's caregiving labor is routinely erased, even in caregivers' own narratives of their labor. Finally, Kaye's discussion addresses how men's selfcare and care work are obscured when later life masculinities are ignored, or when gender remains equated with the 1950's sex role model of separate spheres.

\section{DO LIKE THE WAY I LOOK: OLDER MEN'S PERCEPTIONS AND EXPERIENCES OF AGING AND BODY IMAGE}

L.C. Hurd Clarke, R. Mahal, The University of British

Columbia, Vancouver, British Columbia, Canada

This paper examines the body images of older Canadian men, focusing on their perceptions of and feelings about their changing, aging bodies. We draw upon data from indepth interviews with 22 community-dwelling men, aged 65 to 89 , who were diverse with respect to marital status, level of education, employment history, and household income. Our thematic analysis revealed three key ways that the men perceived and assessed their bodies. First, our participants were either pleased with their overall appearances or unconcerned about how their looks had altered over time. Second, the men emphasized the importance of bodily function over aesthetics as they highlighted their functional qualities (e.g. strength, independence, etc.) and physical activities (e.g. leisure pursuits). Finally, the men articulated concerns about future losses to their health and how such changes might undermine their independence. We consider our findings in 